\title{
Análisis de la satisfacción laboral y desempeño académico profesional del estudiantado graduado en Psicología de la Universidad de Cuenca, Ecuador
}

\author{
Analysis of Job Satisfaction and Professional Academic Performance of Graduates in \\ Psychology from a University in Ecuador
}

\section{Análise de satisfação laboral e desempenho acadêmico profissional dos pós- graduados em psicologia, da Universidade de Cuenca, Equador}

\author{
Guido Leonel Rosales-Jaramillo' \\ Universidad de Cuenca \\ Cuenca, Azuay, Ecuador \\ guido.rosales@ucuenca.edu.ec \\ Andrea Yesenia Rodal-Genovez ${ }^{2}$ \\ Universidad de Cuenca \\ Cuenca, Azuay, Ecuador \\ andrea.rodal@ucuenca.edu.ec \\ Viviana Tatiana Chumbi-Toledo 3 \\ Universidad de Cuenca \\ Cuenca, Azuay, Ecuador \\ viviana.chumbi@ucuenca.edu.ec \\ Román Mauricio Buñay-Andrade 4 \\ Universidad de Cuenca \\ Cuenca, Azuay, Ecuador \\ roman.bunay@ucuenca.edu.ec
}

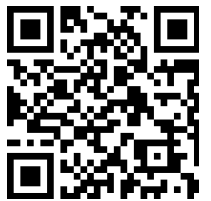

\footnotetext{
${ }_{1}^{1}$ Profesor de segunda enseñanza de Psicología y Pedagogía. Licenciado en Psicología Educativa. Magíster en Educación y Desarrollo del Pensamiento. Coordinador de prácticas pre-profesionales de Psicología Educativa, director del proyecto Seguimiento a Graduados. Catedrático a tiempo completo de la Facultad de Psicología. Director de Carrera de Psicología Educativa de la Universidad de Cuenca. Ecuador.

${ }^{2}$ Licenciada en Psicología Educativa. Magister en Intervención Psicosocial - Familiar. Catedrática en la Facultad de Psicología en la Universidad de Cuenca, Ecuador. Delegada de vinculación con la sociedad ante la Comisión de Seguimiento a Graduados de la Universidad de Cuenca. Coordinadora de vinculación con la sociedad de la Facultad de Psicología.

${ }^{3}$ Licenciada en Ciencias de la Educación especialidad Psicología Educativa. Magister en Educación y Desarrollo del Pensamiento de la Universidad de Cuenca. Catedrática de la Facultad de Psicología, de la Universidad de Cuenca, Ecuador. Investigadora del proyecto Seguimiento a Graduados y facilitadora en procesos de Educación Continua. Docente de educación inicial, básica y bachillerato y psicóloga educativa en ejercicio libre.

${ }^{4}$ Ingeniero Eléctrico de la Universidad de Cuenca. Magister en Energías Renovables de la Universidad de las Fuerzas Armadas. Docenteinvestigador de Estadística en la Facultad de Psicología, de Electrónica de Potencia y Sistemas de Distribución en la Facultad de Ingeniería de la Universidad de Cuenca. Ecuador. Con publicaciones en revistas internacionales y en congresos de ingeniería.
} 
doi: http://dx.doi.org/10.15359/ree.21-3.13

URL: http://www.una.ac.cr/educare

CORREO: educare@una.cr

Recibido 13 de febrero de 2017 • Corregido 12 de julio de 2017 • Aceptado 24 de agosto de 2017 Received 13 de febrero de 2017 • Revised 12 de julio de 2017 • Accepted 24 de agosto de 2017 Recebido 13 de febrero de 2017 • Revisado 12 de julio de 2017 • Aprovado 24 de agosto de 2017

Resumen: Los estudios realizados en las instituciones de educación superior permiten obtener información importante sobre el desempeño profesional. La presente tuvo como objetivo determinar el nivel de satisfacción laboral y establecer correlación entre este constructo y factores extrínsecos que pueden intervenir en esta. El trabajo clasifica como descriptivo correlacional, probabilístico y no experimental. La población registra 1207 profesionales y la muestra calculada fue de 307. Se emplearon métodos teóricos y empíricos tales como: análisis síntesis, histórico lógico, revisión bibliográfica, encuesta y, para el procesamiento estadístico, la prueba Chi Cuadrado en el caso de cruces de variables cualitativas. Se concluyó que existe una fuerte correlación entre la variable dependiente y las variables: salarios, cargos desempeñados y los sectores de empleo; débil la existente entre la satisfacción y el rendimiento académico. Se recomienda que se realice un estudio para una muestra más extensa, con el modelo integrador de satisfacción y que se desarrollen estrategias desde la etapa de formación pregradual para contribuir a mantener altos los niveles en los grupos profesionales graduados de psicología.

Palabras claves: Satisfacción laboral; grupos graduados de psicología; desempeño académico y profesional.

Abstract: Studies conducted in higher education institutions provide important information about professional performance. The present study had as objective to determine the level of job satisfaction, and establish correlation between this construct and extrinsic factors that can intervene in this job satisfaction. This is a descriptive, correlational, probabilistic, and non-experimental work. There is a population of 1207 professionals and the calculated sample was of 307 . Theoretical and empirical methods were implemented, such as analysis, synthesis, historical-logical method, literature review, survey, and for the statistical processing, the Chi-squared test was used to cross qualitative variables. It was concluded that there is a strong correlation between the dependent variable and the variables of salary, positions held, and employment sectors. The relation between satisfaction and academic performance is weak. It is recommended to conduct a study with a more extended sample, with the integrator model of satisfaction, and to develop strategies from the pregraduate training to contribute to keep high levels of satisfaction in professional graduates in psychology.

Keywords: Job satisfaction; graduates in psychology; academic and professional performance.

Resumo: Os estudos realizados em instituições de ensino superior permitem obter informação importante sobre o desempenho profissional. O objetivo desta pesquisa foi determinar o nível de satisfação laboral e estabelecer correlação entre a satisfação e os fatores extrínsecos que podem influencia-la. Esta pesquisa se classifica como descritiva correlacional, com probabilidade e não experimental. A população registra 1207 profissionais dos quais 307 fizeram parte da amostra. Os métodos utilizados foram teóricos e empíricos tais como: análises sínteses, lógico histórico, revisão de literatura, entrevista e o teste Chi Square para o trabalho estatístico, no caso de cruzamentos de variáveis qualitativas. Concluiu-se que existe uma forte correlação entre a variável dependente e outras variáveis: salário, cargo desempenhado e os diferentes setores de emprego; por outro lado, é pouca a correlação existente entre satisfação e desempenho 
acadêmico. Recomenda-se realizar um estudo com uma maior amostra, com o modelo integrador de satisfação e estratégias desenvolvidas a partir da fase de formação universitária, para ajudar a manter níveis mais elevados nos grupos de profissionais em psicologia.

Palavras-chave: Satisfação laboral; estudantes de pós-graduação em psicologia; desempenho acadêmico e profissional.

\section{Introducción}

"Una de las actitudes más estudiadas de los empleados en las organizaciones es la satisfacción de éstos con su trabajo" ha resaltado Raineri (2007, p. 2) en un estudio realizado en diferentes grupos de empleados en Chile; también hace una afirmación con la cual la autoría de este texto coincide: "la satisfacción laboral ha sido estudiada como una consecuencia de la capacidad de la organización y sus administradores por generar un contexto adecuado de trabajo para sus empleados" (p. 2).

La satisfacción laboral es una categoría que revela un estado emocional favorable producto de la percepción de las experiencias laborales y que predispone al sujeto respecto a su trabajo. Son múltiples los factores que pueden incidir y condicionar, es decir, que conllevan a un resultado, que comienza desde la etapa de formación, preparación para el desempeño hasta los perfeccionamientos que se van forjando a lo largo de la vida.

Según las políticas de estudio y los intereses sociales en las universidades del mundo, el perfil de formación del personal de psicología con nivel de pregrado es muy heterogéneo. De acuerdo con González, Ramírez, Castañeda y González (2016), "en Norteamérica, ... el énfasis es con tendencia conceptual, orientada hacia el trabajo de investigación, se brinda información sobre aspectos aplicados y no se ofrece un entrenamiento propiamente dicho" (p. 497).

Desde estas primeras etapas de formación se comienza a gestar lo que en un futuro tributará a la percepción de los niveles de satisfacción con la carrera y con su desempeño profesional. Un plan de estudios bien concebido reafirma la selección vocacional y la orientación profesional, entronca con los determinantes intrínsecos y extrínsecos que conforman el genérico constructo de satisfacción laboral, eje central sobre el cual versa este artículo.

Gallegos, Berra, Benito y López (2014) destacan que en Europa el modelo de estudio concibe, en el último año, prácticas supervisadas antes de comenzar las prácticas independientes y que, en Latinoamérica, la psicología es una carrera donde se hace la especialidad durante un período de 4 a 5 años como máximo, concibiéndose en el plan de estudio, la práctica al final de la carrera.

La formación y desarrollo de habilidades o, en sintonía con la psicología y la pedagogía contemporánea, las competencias constituyen un cimiento clave para que emerja la satisfacción de lo que será su futura profesión, sobre todo si estas últimas, a decir de Tejeda (2011), constituyen "el resultado de variables relacionadas con el desempeño de los profesionales en el variado 
doi: http://dx.doi.org/10.15359/ree.21-3.13

URL: http://www.una.ac.cr/educare

CORREO: educare@una.cr

mundo del trabajo y el desarrollo de la sociedad en general" (p. 4). Se coincide con el autor al valorar la competencia como "una configuración psicológica compleja que tiene su expresión en el desempeño ... y conforma un sentido con una proyección social y profesional en el sujeto" (Tejeda, 2011, p. 7).

Ser competente profesionalmente integra conocimientos, hábitos, habilidades, capacidades, valores, actitudes, destrezas, es "saber ser, saber hacer, saber conocer y saber convivir". Estas hacen posible que una persona se sienta a gusto consigo misma y con los demás sujetos, son un modo de expresión de cada profesional que, cuando se sabe útil, se traduce en autoestima, autovaloración adecuada, autorrealización y, por ende, satisfacción laboral.

Por tanto, se deben observar los diferentes factores que inciden en que los sujetos profesionales sientan un adecuado nivel de satisfacción de sus necesidades laborales, para que, desde el período de formación pregradual, se direccionen en función de estas. La influencia es multifactorial y singular. Cada individuo expresa el grado de satisfacción según sus expectativas, intereses, jerarquía motivacional, aspiraciones, deseos e intenciones; mientras más cerca estén los niveles de aspiración y el de realización, mayor satisfacción tendrá.

Esta temática constituye un aspecto de interés, objeto de estudio de las autoridades y docentes de la institución en función de evitar el abandono escolar y el bienestar psicosocial del estudiantado que se gradúa, que al final se revierte en un desempeño laboral que aporte a la sociedad.

Por lo antes expuesto, el trabajo propone como objetivo determinar la satisfacción laboral en las personas graduadas de la carrera de Psicología de la Facultad de Psicología de la Universidad de Cuenca, Ecuador, y establecer la correlación entre este constructo y factores extrínsecos que pueden intervenir como el salario, los cargos desempeñados, el empleo según sector y el rendimiento académico al concluir estudios.

Este estudio sin precedentes en esta universidad y, por ende, en la facultad, permite trazar estrategias o acciones que tributen al estudio profundo de factores o determinantes que inciden en esta importante categoría psicológica para estar a gusto con el trabajo y con todas las esferas de la vida.

\section{Estado del arte y antecedentes}

Quienes escriben coinciden con Pérez y Fidalgo (1991), en que la satisfacción laboral es un aspecto que ha sido ampliamente estudiado, empezando por los trabajos de Taylor en 1911, los de Happock en 1935, de Mayo en 1945 y así hasta llegar a un punto importante para la psicología humanista con los aportes de A. Maslow en 1954. Interesantes proposiciones que han influido en esta área del conocimiento fueron formuladas por Herzberg desde 1959, denominada teoría bifactorial de la satisfacción, donde postuló la existencia de dos grupos o aspectos laborales. 
Los factores higiénicos (extrínsecos), tales como: salario, cargo desempeñado, seguridad y condiciones en el puesto de trabajo, relaciones interpersonales, políticas de la empresa, entorno físico, compañeros y compañeras de trabajo, jefatura superior inmediata, relación entre dirección y trabajadores en la empresa, el modo en que la institución está organizada, horario de trabajo y la estabilidad en el empleo.

También abordó otro grupo, a los que consideró determinantes de la satisfacción: los factores motivadores (intrínsecos), que serían aquellos consustanciales al trabajo: contenido del mismo, logro, realización, creatividad, dinamismo, novedad, innovación, libertad para elegir su propio método de trabajo, reconocimiento por el trabajo bien hecho, responsabilidad que se asigna, la posibilidad de utilizar sus capacidades, posibilidades de promoción, la atención que se presta a las sugerencias que se hacen y la variedad de tareas que realizan en el trabajo.

Se coincide con el modelo planteado por Herzberg, Mausne y Synderman (1959) que señala que la satisfacción laboral viene generada por los factores motivadores e higiénicos, porque estas conclusiones provienen de la aplicación de instrumentos a grandes poblaciones. Pero vale la pena destacar que se corresponde la insatisfacción con los extrínsecos y la satisfacción con los intrínsecos cuando los del primer grupo van en decrecimiento y los del segundo en incremento; además, este constructo es muy amplio, por lo que se deben considerar más variables que en esta propuesta no aparecen descritas. El estudio realizado en este trabajo presenta la correlación con solo algunos de los primeros.

Uno de los contados trabajos revisados acerca de la satisfacción laboral de 327 personas graduadas de psicología entre 1983 y 1999 en la Pontificia Universidad Católica de Chile, es de la autoría de Makrinov, Scharager y Molina (2005). Los resultados indican que existe satisfacción con el desempeño y refieren la importancia de desarrollar habilidades interpersonales para ejercer la profesión.

Entre los estudios del nivel de satisfacción laboral en profesorado de colegios técnicos en la Dirección Regional de Heredia, Costa Rica, se referencia el trabajo de Ureña y Castro (2009); midieron indicadores de calidad de vida, y los relacionaron con el sentido de coherencia y bienestar laboral.

Ese estudio en Costa Rica permitió conocer cómo la satisfacción laboral guarda estrecha relación con un sin número de categorías, que siguen siendo objeto de estudio en las ciencias sociales, humanísticas, biológicas y de la salud.

Por otro lado, un estudio acerca del grado de satisfacción laboral y condiciones de trabajo, de la Facultad de Ciencias Humanas de la Universidad Autónoma de Baja California, México, asume que la satisfacción laboral se relaciona con la percepción de la experiencia dentro de una organización que tiene el personal, y esta última culmina en un componente emocional, según 
doi: http://dx.doi.org/10.15359/ree.21-3.13

URL: http://www.una.ac.cr/educare

CORREO: educare@una.cr

Abrajan, Contreras y Montoya (2009); se tuvieron en cuenta dimensiones como: seguridad en el trabajo, condiciones de trabajo, relaciones interpersonales, comunicación, motivación, clima organizacional y grado de estrés.

Esta investigación en México, a decir de sus autores, refuerza lo que la ciencia psicológica ha venido reafirmando sobre lo complejo y disímil de las percepciones humanas, su relación con las emociones y el grado de bienestar psicológico de los sujetos trabajadores.

En España, Molina, Ávalos, Valderrama y Uribe (2009) investigaron los factores relacionados con la satisfacción laboral en un hospital médico-quirúrgico de Granada, y señalan que "la insatisfacción de los mismos es la principal dificultad a la que tienen que enfrentarse la cúpula directiva y los gestores de centros sanitarios" (p. 219).

Plantean que es ciencia constituida que los miedos a las autoridades, temores a represalias y el no sintonizar con las posiciones de las jefaturas, productos de los estilos autoritarios de dirección, hacen que se experimente la insatisfacción laboral. También concluyen que esta, junto con el síndrome de desgaste profesional, constituyen un riesgo laboral extendido entre el personal que presta servicios en instituciones públicas y privadas de salud, en relación con las condiciones de trabajo.

Otro estudio de satisfacción laboral fue desarrollado por Solano-Aguilar (2010) en Colombia; reconoce que la satisfacción laboral es uno de los indicadores más recurrentes cuando se persigue conocer cuál es la actitud general de los sujetos hacia su vida laboral, además de incidir sobre otros aspectos como la baja calidad de la prestación, el ausentismo laboral, la propensión al abandono. Agrega que resulta coherente que se asuman actitudes negativas ante el trabajo, como las que describe el estudio, cuando no se está a gusto en el entorno laboral.

En un estudio de seguimiento y evaluación del clima organizacional realizado en Colombia también, Cuadra y Veloso (2007) refieren un alto porcentaje de incremento en variables consideradas positivas en cuanto al clima laboral, tales como satisfacción laboral, disminución de la tensión e incremento del liderazgo, entre otras, lo que se vio reflejado en una mejora en el rendimiento y evitación de riesgos.

También en España se desarrolló una investigación acerca de la satisfacción laboral de personal profesional sanitario, donde Carrillo-García, Solano-Ruíz, Martínez-Roche y GómezGarcía (2013) se apoyaron en la teoría bifactorial de Herzberg et al. (1959), quienes refieren que predominan, en el ambiente físico y psicológico del trabajo, las motivacionales, el contenido del trabajo, responsabilidad, promoción, entre otras.

Un estudio sobre el nivel de satisfacción con la educación en el trabajo de la carrera de Psicología en Cuba (González etal., 2016), caracterizó el alto nivel de satisfacción del estudiantado con la educación en el trabajo; esta fuerte correlación se semeja con tres de las variables que se relacionan en la investigación que se presenta. 
El estudio "Employee job satisfaction and engagement report in USA" (SHRM, 2016) reportó de satisfacción laboral y compromiso de los grupos trabajadores norteamericanos desde el 2005 al 2015. Se evidenció que el tratamiento respetuoso a los empleados y empleadas de todos los niveles fue seleccionado como muy importante, y el más significativo de los aspectos. Esto soporta la teoría de que, aunque es importante el aspecto financiero, la cultura, las conexiones, el sentir apreciados su tiempo y esfuerzos, crean vínculos favorables, determinantes de la satisfacción laboral.

El segundo elemento significativo del trabajo antes citado fueron los salarios, seguidos en tercera posición por los beneficios laborales y en cuarta por la estabilidad laboral.

En la Sede-Ecuador de la FLACSO (Facultad Latinoamericana de Ciencias Sociales) se realizó un estudio (Garcés, 2013) sobre “Determinantes de la insatisfacción laboral en el Ecuador desde una perspectiva de género: Estudio comparativo entre los años 2007 y 2011 ", aborda la satisfacción e insatisfacción laboral en el contexto institucional laboral ecuatoriano, y en ese sentido destaca que existe una mejoría significativa en las condiciones laborales en las que se desenvuelven los grupos trabajadores en el país y, con ello, una mejoría en la satisfacción laboral, aunque aún existen dificultades.

Estos problemas estructurales del mercado laboral también han tenido una especial incidencia en la inserción de jóvenes, pues según datos del año 2005 de la FLACSO (León, 2006, p. 153), "el $27,7 \%$ de la población ecuatoriana es joven, con una edad comprendida entre 18 y 29 años de edad. Es decir, un poco más de uno de cada cuatro ecuatorianos es joven", en este contexto el autor añade la dificultad de ingresar al mercado laboral de este grupo etario y destaca que el acceso "se dificulta por su escasa o inadecuada calificación, así como por su falta de experiencia laboral".

Es positivo que en los últimos años han existido progresos destacables en lo que se refiere a la mejora de la igualdad de oportunidades en el acceso al mercado laboral y en la generación de políticas en contra de la discriminación laboral. Es así como un grupo que presenta muy importantes logros son las personas discapacitadas con avances legislativos comparables con los europeos (USAID y Ministerio de Trabajo y Empleo, 2008).

En el año 2011, según el Centro de Investigación y Análisis de Políticas Públicas (CIAP, 2011), el desempeño del mercado laboral se refleja, con los indicadores de ocupación plena, subempleo y desempleo (Garcés, 2013), cómo se han ido manifestando las posibilidades de empleo en el Ecuador. De igual manera refiere como uno de los principales logros de la administración actual, en el boletín 'Horizonte':

Durante 2010 se registró un importante descenso en la tasa de desempleo y un aumento en la tasa de empleo, lo que marcó una recuperación luego de los efectos que tuvo sobre el mercado laboral la crisis internacional que se presentó en 2009. (CIAP, 2011, p. 4) 
doi: http://dx.doi.org/10.15359/ree.21-3.13

URL: http://www.una.ac.cr/educare

CORREO: educare@una.cr

De manera directa o indirecta, la satisfacción influye en la retención escolar y garantiza la promoción por generaciones, al ser un factor de importancia el nivel de educación que posea la persona, de esta manera, como lo manifiestan Guerrero y Villa-Cox (2012), "Ias personas que poseen un nivel de instrucción superior y postgrado son las que presentan las mayores tasas de ocupación plena" (p. 18). Por lo que se puede inferir, sin absolutizar, que a mayores niveles de instrucción, mejor posibilidad de acceso a un mejor empleo.

Weller (2006, p. 8) destaca que "un desempleo juvenil persistentemente elevado causa preocupación tanto por motivos económicos como sociales". De modo que es fácil inferir que si existe un elevado desempleo juvenil no se está empleando debidamente la mano de obra en esta etapa productiva de la vida. Los efectos sociales que esto acarrea son relevantes puesto que "jóvenes con inserción laboral precaria son una parte importante de la población de riesgo con problemas de adaptación y marginación social" (Weller, 2006. p. 8).

"Se evidencia que el crecimiento de la ocupación plena se ha dado en parte por la expansión del empleo en el sector público" (CIAP, 2011, p. 45); visto desde la perspectiva de la juventud recién graduada, esto reviste una especial significación en cuanto a la seguridad de posibles empleos que ese sector le puede proporcionar (CIAP, 2011).

Respecto a la evolución salarial en el Ecuador en el período 2007-2011, en términos nominales, ha existido un aumento progresivo anual del salario básico unificado; de $\$ 170$ para el año 2007 a \$264 para el año 2011. En el año 2016 el salario básico fue de $\$ 366$ y el nuevo salario básico unificado que rige desde 2017 es de \$375.00, según anunció El Telégrafo (2016).

En las búsquedas realizadas acerca de estudios de satisfacción laboral en la provincia de Azuay, se encontraron pocos trabajos y, respecto a la Carrera de Psicología no se halló ninguno. De los últimos cinco años, se registran los siguientes: "Estudio de la satisfacción laboral en la empresa Cósmica Cía. Ltda" de Jara (2016), de la Universidad Politécnica Salesiana, en Cuenca, con resultados de insatisfacción pre experimento y después de aplicar una estrategia se alcanzó la satisfacción; otro en la Escuela de Enfermería, de la Universidad de Cuenca, con la autoría de Arias, Durán y Galarza (2015), con el objetivo de evaluar el grado de satisfacción y su relación con algunos factores, concluyendo que existía vulnerabilidad en algunos de estos.

Un tercer trabajo proveniente de la Universidad del Azuay, Facultad de Filosofía, Letras y Ciencias de la Educación, Escuela de Psicología Organizacional, en donde Hickel (2014) realizó un"análisis de correlación entre los niveles de inteligencia emocional y los niveles de satisfacción laboral en una muestra de trabajadores de la Empresa Coral Hipermercados", con desfavorables resultados y, un último trabajo realizado por Vélez y Marín (2012), de la Universidad de Cuenca, que evaluó la "Determinación de la satisfacción laboral en la empresa XYZ" cuyos resultados tampoco fueron halagüeños. 
Al analizar la intensidad de la actividad psicológica y física y, la cantidad de tiempo que se pasa una persona trabajadora en su empleo, en el que según Gamero (2003) ocupa un tercio de su período diario, se infiere que este servicio es de suma importancia en sus vidas, por tanto, el nivel de satisfacción que se experimente es una condición clave para el rendimiento y el adecuado desempeño en las restantes áreas de su cotidiana existencia.

El trabajo que se realiza adquiere una gran importancia por las consecuencias que tiene el empleo tanto a nivel personal, como familiar, organizacional y social; por lo que se coincide con la afirmación de que "los empleados satisfechos gozan de mejor salud y viven más años" según Alonso-Martín (2006, p. 49).

Es válido tener la visión de cómo, en investigaciones revisadas, la satisfacción laboral declarada por género, de las personas asalariadas en España, es un juicio relativo; "surge de la comparación implícita entre la situación laboral actual y una situación ideal, la que se experimentaría con el empleo de referencia" (Gamero, 2004, p. 119).

Se presta a reflexión conclusiva que la mencionada proporción (ideal y real) guarda relación con otras variables como son las motivaciones, intereses, cúmulo de conocimientos, habilidades, hábitos, capacidades, actitudes, aptitudes, competencias de los sujetos graduados, unido al personal mentor que han tenido durante su formación; si no existe una correspondencia con relativa cercanía, luego llega la frustración, para la cual no todas las personas tienen un adecuado nivel de tolerancia.

El presente trabajo aborda como constructo genérico la satisfacción laboral en las personas graduadas de la Facultad de Psicología en la Universidad de Cuenca y la relación con factores o determinantes extrínsecos tales como: salario, cargo que desempeña, empleo por sectores y el rendimiento académico obtenido al concluir los estudios.

\section{Marco teórico o referentes conceptuales}

Mucho se ha versado y desde hace más de un siglo, sobre el término de satisfacción laboral. Para realizar un análisis consecuente hay que abordar los que constituyen sus determinantes, factores o variables, según criterio asumido por cada persona autora, que pueden ser extrínsecos e intrínsecos, así como las definiciones y conceptos que, a juicio de quienes escriben el presente trabajo, constituyen los más relevantes.

Un interesante análisis acerca de los determinantes de la satisfacción laboral realizado por varios estudios desde 2000 hasta 2008, hizo Gamboa (2010), donde refiere que Gibson, Ivancevich y Donelly, en el 2001, destacaron el interés de las diferentes organizaciones existentes en el siglo XX, en torno a cómo incrementar la productividad de la organización procurando el bienestar del individuo, debido a que tiene profunda influencia en su comportamiento. 
doi: http://dx.doi.org/10.15359/ree.21-3.13

URL: http://www.una.ac.cr/educare

CORREO: educare@una.cr

Según Gamboa (2010, párr. 2) en el mismo trabajo referido anteriormente:

Existe una serie de factores, determinantes o características que pueden hacer o no sentir satisfecho a un individuo (Galup, Klein y Jiang, 2008). ... En psicología organizacional, el estado emocional placentero o positivo resultante de la experiencia misma del trabajo, se denomina "satisfacción laboral" (Locke, 1976 en Mason y Griffin, 2002; Hancer y George, 2003; Wright y Davis, 2003; Lapierre y Hackett, 2007; Moynihan y Pandey, 2007).

Wright y Davis (citados por Gamboa, 2010) incluyen como determinante de la satisfacción laboral el rol del ambiente de trabajo, formado por dos componentes: las características del trabajo y el contexto del trabajo. Plantean que las determinantes están en tres elementos fundamentales: la satisfacción con el trabajo, la satisfacción con colegas y la satisfacción con la supervisión. Galup et al. (2008) coinciden en que el contexto de trabajo incluye variables muy significativas que forman parte de la gestión y del clima organizacional.

Otra aproximación a las determinantes de la satisfacción laboral la aporta el estudio de Hancer y George (citados en Gamboa, 2010), donde se hace uso del Cuestionario de satisfacción Minnesota para medir un número considerable de facetas de este constructo. Según los autores, estas variables determinan la satisfacción laboral junto a un proceso de dirección científica de planificación, organización, dirección y control, que propicie la innovación y la creatividad en su personal.

A partir de la búsqueda en internet sobre la aplicación del concepto satisfacción laboral y su evaluación, realizada por Pérez (2011) para su tesis de maestría en Psicología Organizacional y Gerencial, en la Universidad Abierta Interamericana de Argentina, encontró 1803 artículos en la década del 2000 al 2010 y se analizaron 388 investigaciones que abarcan casi todos los campos relacionados con el trabajo. No se registró un modelo integrador que explicitara en su totalidad el constructo. A la luz de los estudios de esta mega categoría, aún emergen estudios que muestran nuevas variables o determinantes.

El trabajo de Pérez (2011), a consideración dela autoría del actual, es uno de los más completos de los que hasta este momento se han revisado; propone un modelo de satisfacción laboral, que incluye una amplia gama de factores (externos, organizacionales, interpersonales e intrasubjetivos).

Existen muchas definiciones de satisfacción laboral que Pérez (2011) recrea en su tesis, desde la dada por Taylor en 1911, la de Happock en 1935, la de Mayo en 1945 y la de Maslow en 1954, que desarrolla la jerarquía de necesidades humanas, donde se incluyen aspectos de la satisfacción; inspirado en el trabajo de Maslow, Herzberg en 1959 desarrolló también su teoría bifactorial. 
Vale mencionar, por solo citar algunas, las ofrecidas por Locke (1976), Chiavenato (1986) Bracho (1989) Davis y Newstrom (1991), Sikula (1992), Igbaria y Guimares (1993), Blum y Nayles (1995) Robbins (1996), Spector (1997) Gibson, Ivancevich y Donnelly (2001) Mason y Griffin (2002), Wright y Davis (2003) Schermerhurn, Hunt y Osborn (2005) Foley (2006), Morillo (2006) Andresen, Domsch y Cascorbi (2007) y Lee y Chang (2008).

Las diferentes posiciones declaradas en sus definiciones no son excluyentes, sino que cada una hace alusión o resalta diferentes enfoques o variables de un mismo fenómeno. De alguna manera, coinciden en que la satisfacción laboral es un buen presagio del rendimiento óptimo, de la eficiencia, la eficacia, de la productividad, de permanencia en el trabajo, además que guarda relación con otras categorías importantes en la vida como la familia, los grupos, los afectos, el liderazgo, la comunicación, la cultura y el clima organizacional, y la motivación, entre otras.

En el presente trabajo se está en consonancia con la definición que plantea Pérez (2011, p. 89), donde refiere que la satisfacción laboral "es la conjunción de una serie de actitudes frente a distintos aspectos que influyen en grados variables sobre el empleado para obtener lo que se denomina Satisfacción laboral".

Las empleadas y empleados satisfechos laboralmente quieren conservar en todo lo posible su trabajo, muestran solicitud al proceso de capacitación para mejorar el conocimiento de su área, disposición a realizar tareas extras a las que tienen en su plan, armonizan con el resto del personal, ven más aspectos positivos que negativos en el entorno, son cada vez personas más competitivas y competentes sin ser arribistas, son proactivas, propositivas, tienen ganas de aplicar nuevos conocimientos y tecnologías, de innovar, de crear, desbordan alegría, gozan de mejor salud, calidad de vida y todo esto se refleja en su vida íntima, particular, personal, familiar y social.

\section{Metodología}

El trabajo clasifica como descriptivo correlacional, no experimental y probabilístico. Se realizó en Ecuador, Universidad de Cuenca, Facultad de Psicología de la Carrera de Psicología. Un estudio sin precedentes en la institución, que se efectuó con un grupo de estudiantes que se graduó en el período desde 1983 hasta 2014.

La población registra 1207 profesionales que obtuvieron el título en esa etapa. Debido a la imposibilidad de ubicar a los sujetos seleccionados mediante muestreo aleatorio estratificado, para la selección de la muestra se tuvieron en cuenta los siguientes criterios de inclusión: ubicación geográfica, disponibilidad de tiempo y voluntad de los sujetos. Se optó por el tipo de muestreo no probabilístico. En cuanto al nivel de confianza se estableció un 95\% y un margen de error de $4.83 \%$. Se aplicaron nuevos valores a la fórmula y la muestra final tuvo la composición de $\mathbf{3 0 7}$ personas graduadas, número efectivamente alcanzado en el estudio. 
doi: http://dx.doi.org/10.15359/ree.21-3.13

URL: http://www.una.ac.cr/educare

CORREO: educare@una.cr

Para la recolección, procesamiento y fundamentación de la información, se emplearon métodos teóricos como análisis-síntesis e histórico-lógico; los empíricos utilizados fueron la revisión bibliográfica y documental impresa y digital $\mathrm{y}$, una encuesta que se aplicó online y administrada por personal encuestador entrenado para este propósito (Anexo A y B), la cual fue diseñada por el equipo de trabajo y validada por un grupo docente universitario interno y externo, en calidad de jueces y personal experto, para obtener un cúmulo de información en el proyecto Seguimiento a graduados, de la cual se tomaron solo algunos datos para este trabajo como la satisfacción laboral, salarios, cargos desempeñados, empleo por sectores y rendimiento académico, que hicieron posibles la correlación entre las variables.

Para el procesamiento, análisis y presentación de la información se emplearon métodos y técnicas estadísticos al considerar como variable dependiente la satisfacción laboral y las independientes el salario, los cargos desempeñados, empleo por sectores y el rendimiento académico. La información se recogió y procesó en el programa Excel. Se utilizó el SPSS (Paquete Estadístico para las Ciencias Sociales) para Windows versión 20.0, para comprobar la relación entre variables. Se utilizó la prueba de Chi Cuadrado que requiere como condición el uso de variables cualitativas nominales $u$ ordinales en las cuales se desea verificar, como hipótesis nula, la dependencia de las variables analizadas. Se realizaron tablas y figuras.

\section{Resultados, análisis y discusión}

Los resultados obtenidos de la encuesta que se aplicó a los 307 graduados de la carrera de Psicología de la Facultad de Psicología de la Universidad de Cuenca se presentan a continuación, en las tablas y figuras con discusiones, comentarios o cuestionamientos. Se parte de los datos netos de las variables independientes: salario, cargos desempeñados, empleo por sectores y rendimiento académico y, la variable dependiente: la satisfacción laboral.

En relación con los salarios mensuales que devengan los graduados de la carrera Psicología, se observa que el 3,5\% gana entre $\$ 2000.00$ y más dólares americanos; entre $\$ 2000.00$ y $\$ 1501.00$ el 3,8\%; apenas el $8,3 \%$ gana entre $\$ 1500.00$ y $\$ 1001.00$. El $38,2 \%$ gana entre $\$ 1000.00$ y $\$ 751.00$ dólares; el 33\% gana entre $\$ 750.00$ y $\$ 501.00$ dólares; entre el $8 \%$ y el $1 \%$ oscilan los salarios entre $\$ 500.00$ y menos del salario básico mensual del sector público y privado en el país.

Se puede apreciar, de lo citado anteriormente, que las mayores cifras de salarios oscilan entre los $\$ 500.00$ y $\$ 1000.00$ dólares; estas sobrepasan el salario básico mensual de Ecuador en este 2017 que es de $\$ 375.00$. Es un buen augurio para profesionales de la psicología, que les permite satisfacer sus necesidades elementales y otras. Aunque este factor extrínseco no está registrado por estudios del tema como uno de los aspectos que tributan a la satisfacción laboral, es un indicador importante en la vida, por lo que sabe permite una economía aceptable. 
Según investigaciones revisadas que se describen en el texto del artículo, se hace evidente que los salarios devengados por la mayoría de quienes se desempeñan en el área de la psicología, en el sector público como en el privado y en la docencia o la clínica, les resulta gratificante.

En relación con los cargos que desempeñan, la encuesta reflejó que el $28 \%$ de se desempeña como docente de educación inicial; el 23\% como profesional de psicología educativa; el $21 \%$ como docente de educación básica; un $6 \%$ ejerce como docente de universidad, el $4 \%$ como docente de bachillerato; un 1\% como personal orientador vocacional y el $17 \%$ en otros empleos.

En resumen, el mayor porcentaje se desempeña como docente en el área educativa, pero las disímiles posibilidades de cargos en los que se emplean van desde la docencia en diferentes niveles de enseñanza, pasando por la labor de orientación hasta el área asistencial. Se coincide con lo que refieren las investigaciones en cuanto a que las posibilidades de acceder, ascender y realizarse una vez graduados o graduadas es disímil y versátil, no se ciñe a una sola actividad.

Tabla 1: Empleo por sectores de estudiantado graduado de la carrera de Psicología

\begin{tabular}{lcc}
\multicolumn{1}{c}{ Categoría } & Frecuencia & Frecuencia relativa \\
\hline Público & 230 & $75 \%$ \\
Privado & 49 & $16 \%$ \\
Independiente & 7 & $2 \%$ \\
Otros, especifique & 4 & $1 \%$ \\
No trabaja & 17 & $6 \%$ \\
\end{tabular}

Nota: Encuesta a personas graduadas, elaboración propia.

La Tabla 1 muestra que la mayoría de sujetos encuestados se desempeña en el sector público; esto permite inferir que las posibilidades de empleo en este fragmento social se van ampliando, y a su vez se corresponde con el estudio realizado por Garcés (2013) de la FLACSO respecto a que hay una mejoría significativa en las condiciones laborales en las que se desenvuelven los grupos trabajadores en Ecuador, aunque persistan algunas dificultades. 
doi: http://dx.doi.org/10.15359/ree.21-3.13

URL: http://www.una.ac.cr/educare

CORREO: educare@una.cr

Tabla 2: Rendimiento académico del estudiantado graduado de la carrera Psicología

\begin{tabular}{ccc}
\hline Categoria & Frecuencia & Frecuencia relativa \\
\hline Sobresaliente & 101 & $33 \%$ \\
Muy Buena & 195 & $63 \%$ \\
Buena & 11 & $4 \%$ \\
& 307 & \\
\hline
\end{tabular}

Nota: Encuesta a personas graduadas, elaboración propia.

En la Tabla 2 se muestran los rendimientos del estudiantado graduado encuestado, esto se determinó por las notas de grado obtenidas al final de la carrera, las que se categorizaron en sobresaliente para los puntajes entre 100 y 90; muy buena para los puntajes entre 89 a 80 y, buena entre 79 y 70 puntos. Nadie tuvo puntuación de regular. Esto habla a favor de su calidad, pues el mayor por ciento está en las dos mejores y también se pudiera inferir el esfuerzo de la planta docente para formar a sus estudiantes, en la facultad de Psicología de la Universidad de Cuenca.

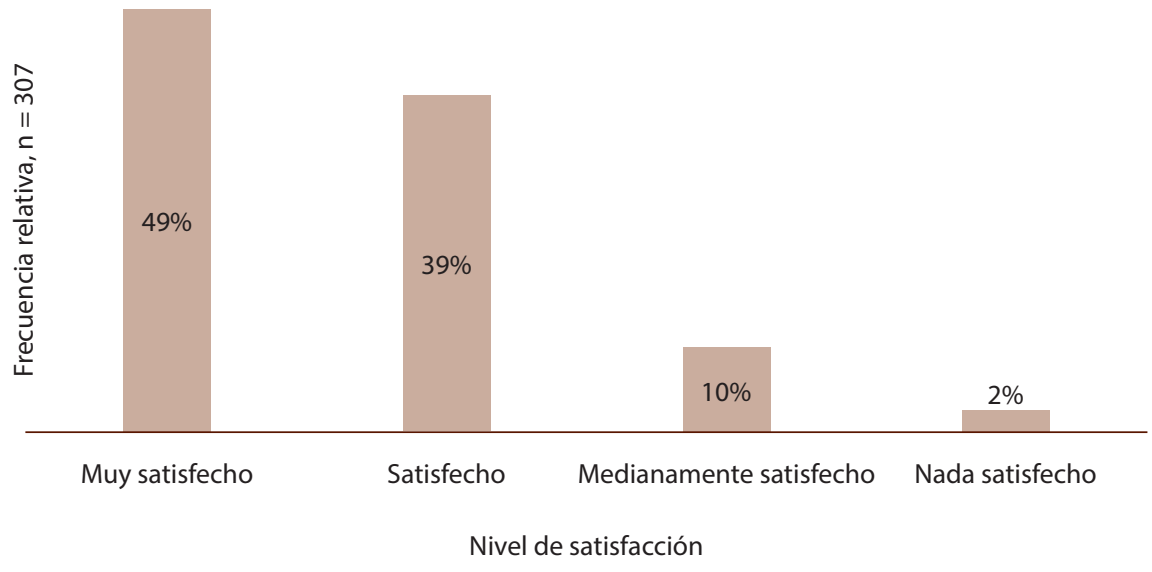

Figura 1: Nivel de satisfacción laboral de estudiantado graduado de Psicología Nota: Encuesta a personas graduadas, elaboración propia.

Esta Figura 1 constituye el eje medular de este artículo. Es evidente que un alto porcentaje muestra satisfacción o mucha satisfacción laboral y esos datos hablan a favor de que puedan estar incidiendo determinantes extrínsecos e intrínsecos en este constructo, los cuales no se exploraron. Esta es una limitante del trabajo, al que se le dará continuidad en el presente año. De igual manera llama la atención, por baja que sea la cifra, del grupo que está medianamente y nada satisfecho en su labor. Será un reto explorar el motivo que subyace en esta insatisfacción. 
Los altos resultados de satisfacción coinciden con los estudios revisados tanto en las personas graduadas de diferentes áreas del mundo laboral como en los del área de la psicología. Por ejemplo, el estudio del reporte en USA (SHRM, 2016) determinó que un 88\% de satisfacción en el trabajo, la más grande proporción desde el 2002; igual se coincide con la investigación realizada por Garcés (2013) en la FLACSO Ecuador, que refiere una mejoría sustancial en la satisfacción laboral. Vale destacar la alta satisfacción en la carrera de Psicología en Villa Clara (González et al., 2016), con también un 88\%.

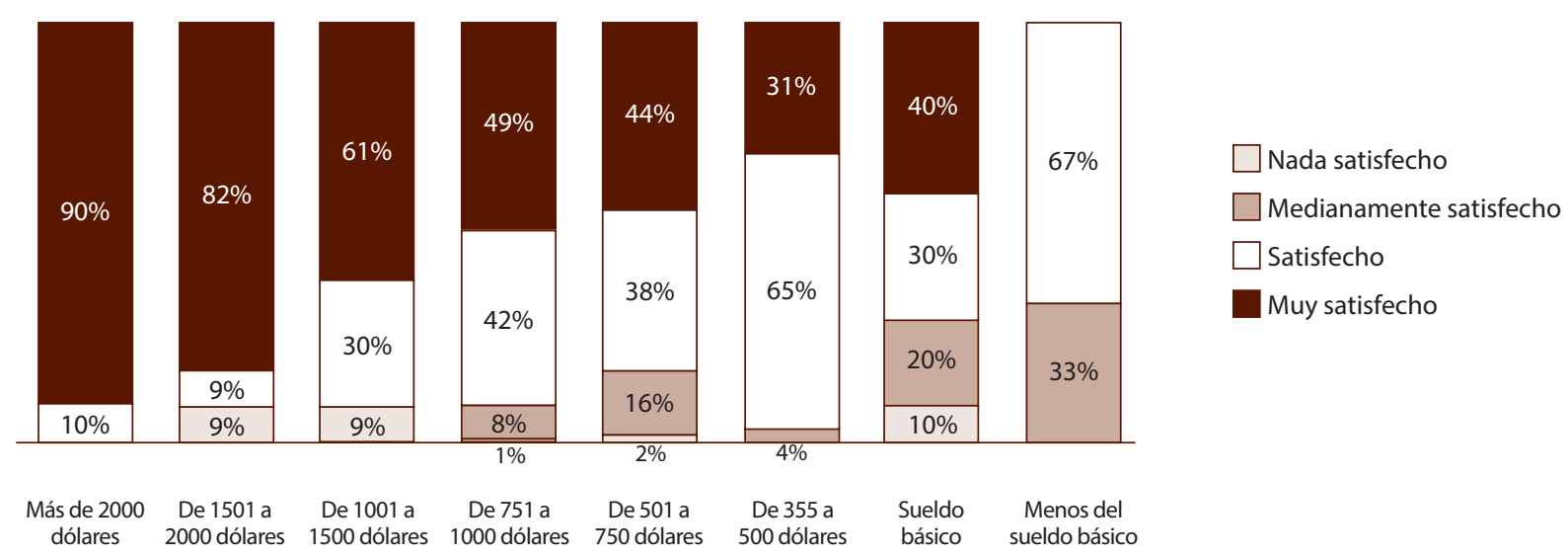

Figura 2: Relación entre salarios y satisfacción laboral de estudiantado graduado de Psicología. Nota: Encuesta a personas graduadas, elaboración propia.

La Figura 2 evidencia lo corroborado al aplicar la prueba de Chi cuadrada de Pearson y se verificó que los ingresos se relacionan con el nivel de satisfacción laboral de manera directa con un nivel de significancia $<, 01$.

En el estudio de reporte en USA (SHRM, 2016) se evidenció que el segundo elemento más significativo fueron los salarios. Se coincide en que de manera tendencial se demuestra que los salarios conforman los niveles de satisfacción laboral, sin dejar de tomar en cuenta que esto fluctúa en dependencia de otros factores. Por el contrario, en el estudio realizado en Argentina por Pérez (2011), se puede ver el salario insuficiente como factor de insatisfacción más resaltante.

En la anterior Figura 3 se visualiza lo corroborado con la aplicación de la prueba Chi cuadrado de Pearson y se comprobó que los cargos actuales se relacionan con el nivel de satisfacción laboral de manera directa con un nivel de significancia $<, 01$. Los cargos forman parte de los determinantes motivadores de la satisfacción laboral, como aspectos consustanciales al trabajo que pueden devenir en posibles promociones, responsabilidades relevantes, reconocimientos a sus aportes, realización profesional, por citar algunos. 
doi: http://dx.doi.org/10.15359/ree.21-3.13

URL: http://www.una.ac.cr/educare

CORREO: educare@una.cr

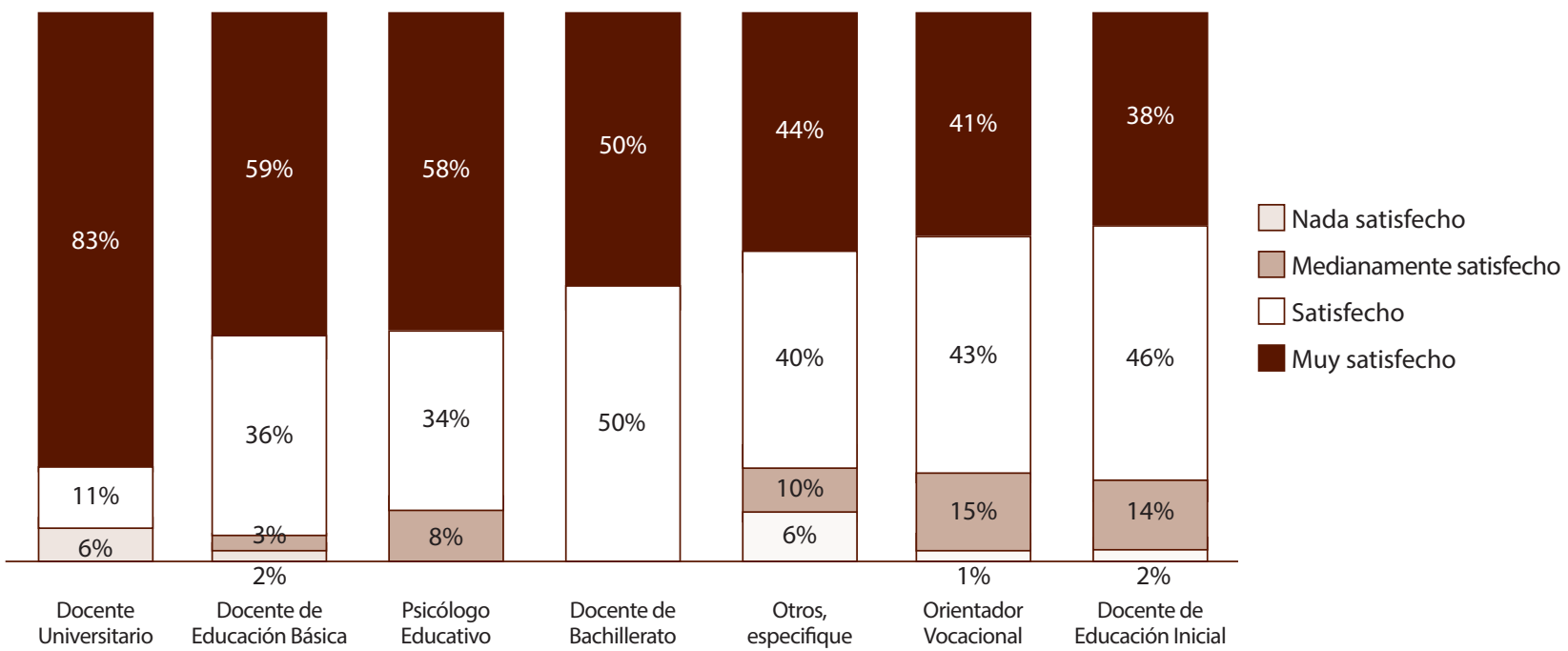

Figura 3: Relación de cargo actual y satisfacción de estudiantado graduado de Psicología Nota: Encuesta a personas graduadas, elaboración propia.

Se aplicó la prueba Chi cuadrado de Pearson y se constató que el empleo por sector se relaciona con el nivel de satisfacción laboral de manera directa con un nivel de significancia < ,01. El alto porcentaje de empleo en el sector público, como puede observarse en la Figura 4, como factor extrínseco o higiénico a decir de Herzberg et al. (1959), puede implicar a modo inferencial una relativa estabilidad y seguridad en el trabajo; cuando una sociedad apuesta por darles oportunidad a sus graduados y graduadas es un elemento de progreso evidente, máxime cuando esta profesión en el mundo es considerada básicamente de élite; hoy se les da esta posibilidad para atender hasta dentro de las propias instituciones educativas a toda diversidad de individuos y sus familias.

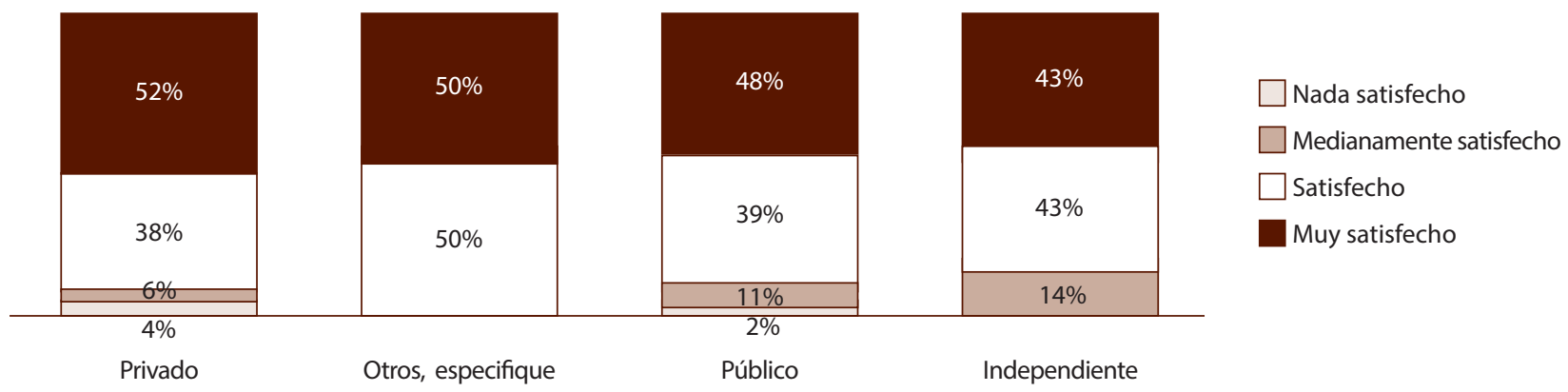

Figura 4: Relación empleo por sector y satisfacción de estudiantado graduado de Psicología Nota: Encuesta a personas graduadas, elaboración propia. 
Los problemas estructurales del mercado laboral, tal como refieren Gamboa (2010) y Weller (2006) de la FLACSO, han tenido una especial incidencia en la inserción de jóvenes al empleo, según datos de León (2006) en el año 2005, el 27,7\% de la población ecuatoriana es joven, con una edad promedio de 23 años, es decir, un poco más de una de cada cuatro personas ecuatorianas es joven y gran cantidad no puede emplearse.

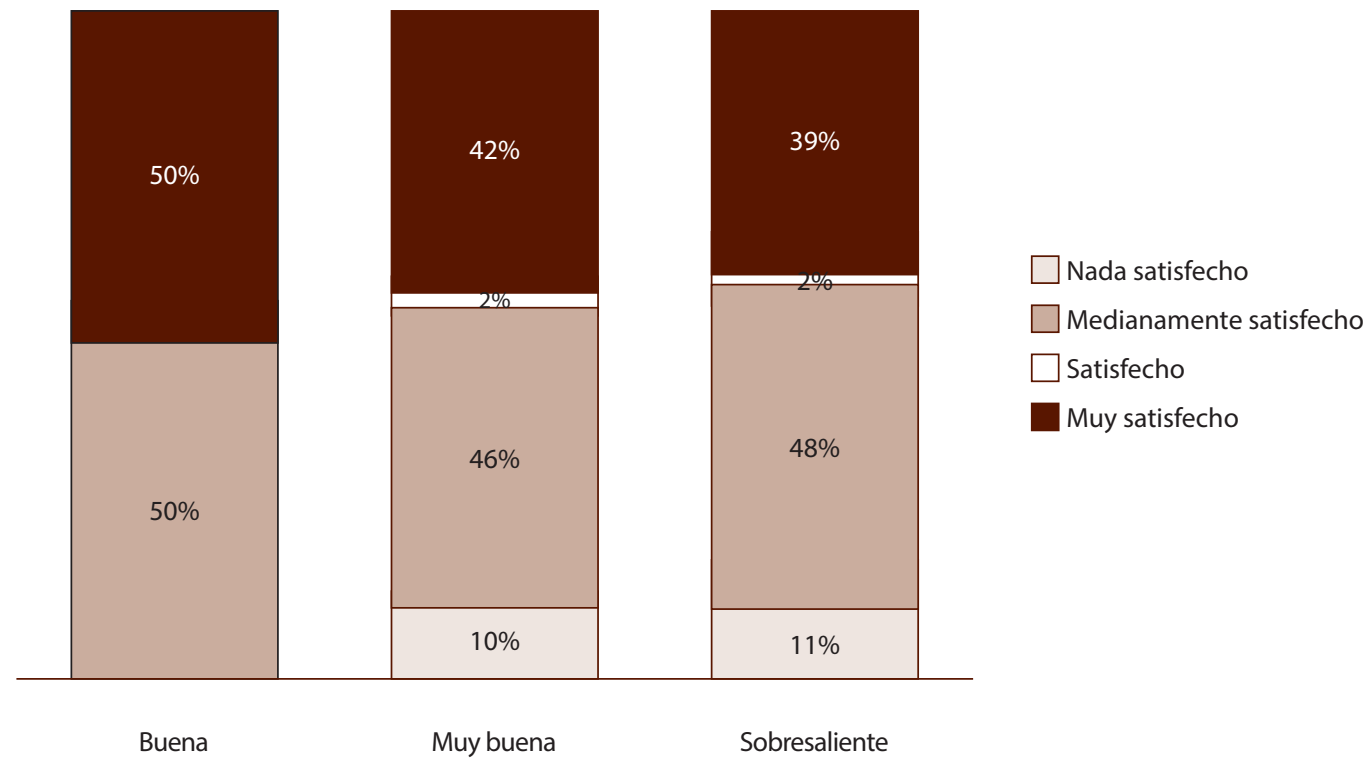

Figura 5: Relación rendimiento académico y nivel de satisfacción de estudiantado graduado de Psicología

Nota: Encuesta a personas graduadas, elaboración propia.

La Figura 5 evidencia que el record académico por sector no se relaciona con el nivel de satisfacción laboral. El nivel de significancia es de 56,8\%.

Este es el único determinante que ofrece una débil correlación, puede prestarse a múltiples interpretaciones, pues parece contradictorio con los anteriores resultados presentados. Sin caer en posiciones de extrema subjetividad, porque no se exploraron los motivos, pueden inclinarse las reflexiones hacia el alto nivel de expectativas en relación con su futura ubicación que regularmente tiene una persona graduada con altos puntajes en su recorrido final de notas. Tal vez entren a jugar otros factores o determinantes que no se exploraron con la encuesta que aplicó este estudio, pues como se ha podido leer en este artículo, son múltiples y diversas las variables que pueden incidir, como así es de compleja y suigéneris la personalidad.

En resumen, si se logra organizar en el plan de estudios de la carrera, que los alumnos y las alumnas vayan engrosando el cuerpo de su hoja de vida o curriculum vitae, si se les estimula 
doi: http://dx.doi.org/10.15359/ree.21-3.13

URL: http://www.una.ac.cr/educare

CORREO: educare@una.cr

para que participen en congresos o eventos nacionales e internacionales, en trabajos científicos estudiantiles, en investigaciones desde la educación en el trabajo conjunto con docentes o individualmente, en desarrollar habilidades en la redacción científica con ensayos, monografías, revisión bibliográfica, artículos, entre otros, con la calidad requerida, llevarán un buen historial académico y les favorecerá en su futuro empleo.

En los últimos años, en la Facultad de Psicología, el estudiantado realiza los proyectos de servicio a la comunidad (160 horas según lo establece la LOES), su primer contacto con el área laboral. Esta vinculación con la sociedad se constituye en un camino de doble vía, el cual, por un lado, le brinda la posibilidad de desarrollar las competencias de la psicología al poder desarrollarse en escenarios reales de su futura profesión; y por otro, le permite un crecimiento personal al ampliar sus perspectivas y poder contribuir activamente en las comunidades en las que interviene. Se tiene la satisfacción de que, en un alto porcentaje, se involucra y excede las horas requisito y pasa a formar parte de los proyectos de manera indefinida; además de enseñarle a amar y valorar su trabajo por encima de todas las cosas, donde quiera que se encuentre.

\section{Conclusiones}

- La realización del artículo permitió conocer teorías y modelos integradores actuales para profundizar y explorar en un constructo vital en el mundo del trabajo como lo es la satisfacción laboral.

- El estudio aporta una valiosa información del estudiantado graduado en relación con los determinantes extrínsecos e intrínsecos de la satisfacción laboral, que pueden ser fuente valiosa de investigaciones posteriores.

- Se evidencia un alto porcentaje de satisfacción laboral en las personas graduadas encuestadas de la carrera de Psicología. Este es un elemento gratificante cuando se conoce que este constructo ha sido estimado como un factor crucial en la vida del trabajo, pues no es fácil conseguir que una persona realice un trabajo con calidad y eficacia si no se encuentra satisfecha, aun cuando existen organizaciones en las que se considera al sujeto trabajador como un homo economicus, ausente de intereses, deseos, expectativas y necesidades.

- Se puede apreciar que los salarios que devengan sobrepasan el básico de otros sectores públicos y privados de Ecuador en este 2017, que el mayor por ciento ejerce como docente en el área educativa, se desempeña en el sector público y en su graduación se categorizaron con notas sobresalientes.

- La correlación fue alta entre la satisfacción laboral del estudiantado graduado y las variables salarios, cargos desempeñados y los sectores de empleo, determinantes o 
factores externos que deben ser considerados por gobiernos y entes empleadores tanto públicos como privados, para posibilitar la estabilidad laboral y bienestar de su personal.

- Resultó débil la correlación entre la variable satisfacción laboral y el rendimiento académico, lo cual constituyó un asombro para el equipo de trabajo y puso nuevos retos en cuanto al proceso de formación de las personas graduadas y de la propia investigación, para cuidar de no dejar variables sueltas a merced de la subjetividad de las personas investigadoras.

- Se evidencia que las expectativas laborales de los grupos profesionales podrían no estar siendo satisfechas debido a factores encontrados mediante la investigación, tal es el caso de los escenarios de inserción laboral que mayoritariamente están ubicados en el magisterio, es decir, como docentes, y no como psicólogos o psicólogas, que es para lo que se formaron en la universidad.

- Se evidencia que el salario es un determinante para el nivel de satisfacción laboral de profesionales de la psicología.

- Se puede constatar, mediante los resultados obtenidos, que el nivel de educación en el que se desenvuelve cada profesional de la psicología determina su satisfacción, donde se valora mucho más el nivel universitario y queda el nivel inicial de educación como el escenario laboral que menos satisfacción le brinda al estudiantado graduado de las carreras de psicología.

\section{Recomendaciones}

- Enel procesoformativo desarrollarestrategias integrales de dimensiones contemplativas de las áreas cognitivas, afectivas, conductuales y actitudinales, que postulen de una manera el entrenamiento en la resolución de disímiles problemas en las esferas de su futuro mundo laboral y de las relaciones interpersonales.

- Aplicar el modelo integrador de satisfacción laboral que ofrece Pérez (2011) en su trabajo, el cual incluye la más amplia gama que se ha revisado de factores externos, organizacionales, interpersonales e intrasubjetivos.

\section{Referencias}

Abrajan, M. G., Contreras, J. M. y Montoya, S. (2009). Grado de satisfacción laboral y condiciones de trabajo: Una exploración cualitativa. Enseñanza e investigación en psicología, 14(1), 105118. Recuperado de http://www.redalyc.org/articulo.oa?id=29214108 
doi: http://dx.doi.org/10.15359/ree.21-3.13

URL: http://www.una.ac.cr/educare

CORREO: educare@una.cr

Alonso-Martín, P. (2006). Diferencias en la percepción de la satisfacción laboral en una muestra de personal de administración. Boletín de Psicología, 88, 49-63. Recuperado de http:// www.uv.es/seoane/boletin/previos/N88-3.pdf

Arias, M. A., Durán, J. B. y Galarza, E. C. (2015). Grado de satisfacción laboral del personal de enfermería y factores asociados en los servicios de clínica, cirugía y pediatría del hospital José Carrasco Arteaga, cuenca 2014 (Tesis de licenciatura). Universidad de Cuenca, Ecuador. Recuperado de http://dspace.ucuenca.edu.ec/bitstream/123456789/21720/1/TESIS.pdf

Carrillo-García, C., Solano-Ruíz, M., Martínez-Roche, M. E. y Gómez-García, C. (2013). I. Influencia del género y edad:Satisfacción laboral de profesionales sanitarios. Revista Latinoamericana Enfermagem, 21(6), 1314-1320. doi: https://doi.org/10.1590/0104-1169.3224.2369

Centro de Investigación y Análisis de Políticas Públicas (CIAP). (2011). Algunas cifras que preocupan en el mercado laboral. Horizonte N. ${ }^{\circ}$ 31, 4-9.

Cuadra, A. y Veloso, C. (2007). Liderazgo, clima y satisfacción laboral en las organizaciones. Revista Universum, 2(22), 40-56. doi: https://doi.org/10.4067/S0718-23762007000200004

El Telégrafo. (19 de diciembre de 2016). También hubo consenso en 16 de las 21 mesas sectoriales productivas. \$375 es el nuevo salario básico unificado que regirá desde 2017. El Telégrafo, Sección Economía. Recuperado de http://www.eltelegrafo.com.ec/noticias/economia/8/ usd375-sera-el-nuevo-salario-para-2017

Gallegos, M., Berra, M., Benito, E. y López, W. (2014). Las nuevas dinámicas del conocimiento científico y su impacto en la psicología latinoamericana. Psicoperspectivas, 13(3), 106-117. doi: https://doi.org/10.5027/psicoperspectivas-Vol13-Issue3-fulltext-377

Galup, S. D., Klein , G., \& Jiang, J. J. (2008). The impact of job characteristics on is employee satisfaction: A comparison between permanent and temporary employees. Journal of Computer Information Systems, 48(4), 58-68.

Gamboa, E. J. (2010). Satisfacción laboral: Descripción teórica de sus determinantes. Revista PsicologiaCientífica.com Recuperado de http://www.psicologiacientifica.com/satisfaccionlaboral-descripcion-teorica-de-sus-determinantes

Gamero, C. (2003). Análisis económico de la satisfacción laboral (Tesis doctoral). Universidad de Málaga, España. Recuperado de http://www.eumed.net/tesis-doctorales/cgb/

Gamero, C. (2004). Satisfacción laboral de los asalariados en España. Especial referencia a las diferencias por género. Cuadernos de economía, 27, 109-146. Recuprado de https://www. uam.es/departamentos/economicas/analecon/analisis economico es/cuadernos de economia/numeros/74/74 05.pdf 
Garcés, M. A. (2013). Determinantes de la insatisfacción laboral en el Ecuador desde una perspectiva de género: Estudio comparativo entre los años 2007 y 2011 (Tesis de maestría). Flacso, Ecuador. Recuperado de http://repositorio.flacsoandes.edu.ec/handle/10469/6992\#. WTsOWBOGNBw

González, L., Ramírez, I., Castañeda, Á. y González, G. (2016). Nivel de satisfacción con la educación en el trabajo de la carrera de Psicología en Villa Clara. Educación Médica Superior, 30(3), 496-514. Recuperado de http://scielo.sld.cu/scielo.php?script=sci arttext \&pid=S0864-21412016000300005

Guerrero, A. y Villa-Cox, R. (2012). Mercado de trabajo en el Ecuador y su análisis desde la oferta laboral. Investigación y Desarrollo, 18, 17-22.

Herzberg, F., Mausner B. y Snyderman B. B. (1959). The motivation to work. New York: Wiley.

Hickel, M. G. (2014). Análisis de correlación entre los niveles de inteligencia emocional y los niveles de satisfacción laboral en una muestra de trabajadores de la empresa Coral Hipermercados. Universidad del Azuyay, Cuenca, Ecuador. Recuperado de http://dspace.uazuay.edu.ec/ bitstream/datos/3955/1/10559.pdf

Jara, H. (2016). Estudio de la satisfacción laboral en la empresa Cósmica Cía. Ltda. Universidad Politécnica Salesiana (Proyecto). Cuenca, Azuay. Ecuador. Recuperado de http://dspace. ups.edu.ec/bitstream/123456789/12386/1/UPS-CT006466.pdf

León, M. (2006). Políticas, programas y proyectos de inserción laboral para la juventud del Ecuador. En L. Martínez (Ed.), Jóvenes y mercado de trabajo en el Ecuador (pp. 153-184). Recuperado de http://repositorio.cepal.org/bitstream/handle/11362/31961/S2006364 es.pdf;jsessionid=E8074F0005A654FFAEC3CB8818D43FC4? sequence $=1$

Makrinov, N., Scharager, J. y Molina, L. (2005). Situación actual de una muestra de psicólogos egresados de la Pontificia Universidad Católica de Chile. Psykhe, 14(1), 69-77. doi: https:// doi.org/10.4067/S0718-22282005000100006

Molina, J. M., Ávalos, F., Valderrama, L. J. y Uribe, A. F. (2009). Factores relacionados con la satisfacción laboral de enfermería en un hospital médico-quirúrgico. Investigación y Educación en Enfermería, 27(2), 218-225. Recuperado de http://www.redalyc.org/articulo. oa?id=105213195007

Pérez, J. y Fidalgo, M. (Redactores). (1991). NTP 394. Satisfacción laboral: Escala general de satisfacción. España: Ministerio de Trabajo y Asuntos Sociales en España y el Instituto Nacional de Seguridad e Higiene en el Trabajo. Recuperado de http://www.insht.es/ InshtWeb/Contenidos/Documentacion/FichasTecnicas/NTP/Ficheros/301a400/ntp 394. pdf 
doi: http://dx.doi.org/10.15359/ree.21-3.13

URL: http://www.una.ac.cr/educare

CORREO: educare@una.cr

Pérez, P. (2011).Satisfacción laboral. Una revisión actual de la aplicación del concepto de satisfacción laboral y su evaluación. Hacia un modelo integrador (Tesis de maestría). Universidad Abierta Interamericana. Argentina. Recuperado de http://imgbiblio.vaneduc.edu.ar/fulltext/files/ TC110592.pdf

Raineri, A. (2007). Distribución de satisfacción laboral en diferentes grupos de empleados en Chile: Similitud con culturas individualistas. Estudios de Administración, 14(2), 2007, 1-42. Recuperado de http://estudiosdeadministracion.unegocios.cl/estudios/Collection files/ E A 2007 Vol14 N2 Raineri.pdf

Society for Human Resourse Mangamente (SHRM). (2016). Employee job satisfaction and engagemen. Rivitalizingachanging workforce.Aresearchreport.Recuperado dehttps://www. shrm.org/hr-today/trends-and-forecasting/research-and-surveys/Documents/2016Employee-Job-Satisfaction-and-Engagement-Report.pdf

Solano-Aguilar, S. (2010). Satisfacción laboral en profesionales de enfermería. Revista Cuidarte, 1(1), 53-62. doi: https://doi.org/10.15649/cuidarte.v1i1.74

Tejeda, R. (2011). Las competencias y su relación con el desempeño y la idoneidad profesional. Revista Iberoamericana de Educación, 55(4), 1-12.

Ureña, P. y Castro, C. (2009). Calidad de vida, sentido de coherencia y satisfacción laboral en profesores(as) de colegios técnicos en la Dirección Regional de Heredia. Revista Electrónica Educare, 13(1), 71-87. Recuperado de http://www.revistas.una.ac.cr/index.php/EDUCARE/ article/view/1477/1397

USAID y Ministerio de Trabajo y empleo (MET). (2008). Discriminación en el mercado laboral ecuatoriano: Condición de género, particularidades indígenas y personas con discapacidad (Proyecto Reforma Laboral-Ecuador). Ponencia para los Foros por los Derechos Fundamentales del Trabajo [Diapositivas en PowerPoint]. Recuperado de http://www. ceime.net/foros/images/foros/discriminacin $\% 20$ y 20 mercado\%20laboral.pdf

Vélez, P. A. y Marín, E. G. (2012). Determinación de la satisfacción laboral en la empresa XYZ (Tesis de pregrado). Universidad de Cuenca, Ecuador. Recuperado de http://dspace.ucuenca. edu.ec/handle/123456789/1056

Weller, J. (2006). Prólogo. En L. Martínez (Ed.), Jóvenes y mercado de trabajo en el Ecuador (pp. 7-10). Ecuador: FLACSO. Recuperado de http://repositorio.cepal.org/bitstream/ handle/11362/31961/S2006364 es.pdf;jsessionid=E8074F0005A654FFAEC3CB8818D43F C4? sequence $=1$ 
doi: http://dx.doi.org/10.15359/ree.21-3.13

URL: http://www.una.ac.cr/educare

Anexo $A$

CORREO: educare@una.cr

Encuesta I

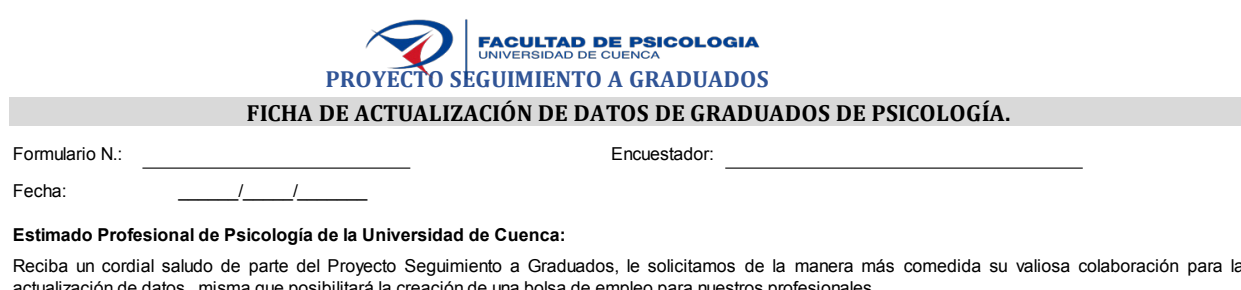

Reciba un cordial saludo de parte del Proyecto Seguimiento a Graduados, le solicitamos de la manera más comedida su valiosa colaboración para la actualización de datos, misma que posibilitará la creación de una bolsa de empleo para nuestros profesionales.

\section{DATOS DEMOGRÁFICOS}

1. DATOS GENERALES DEL GRADUADO

1.1 Nombres completos:

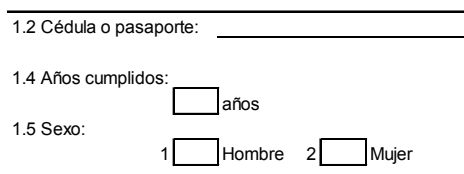

2.1. INFORMACIÓN DE GRADO:

2.1. INFORM
Facultad:
Carrera:

Año de ingreso:

Año de egreso:

Título obtenido:

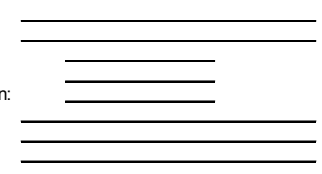

2.2 INFORMACIÓN DE POSGRADO:

¿Ha realizado algún estudio de posgrado? \begin{tabular}{l|l}
1 \\
2
\end{tabular}

(Si su respuesta es negativa, por favor pase al cuestionario de seguimiento a graduados)

2.2.1. POSGRADO:

País:

Universidad:

Facultad:

Tipo de Programa

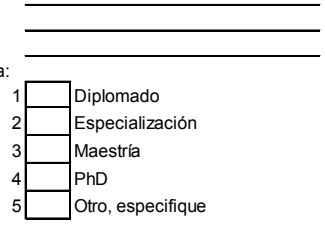

Modalidad de Estudios:

1 Presencial

2 Semipresencial

Título obtenido:

A distancia

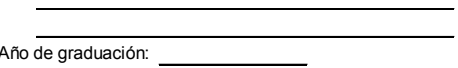

Nota de grado:

\begin{tabular}{l|l|l}
1 & & Sobresaliente (90 a 100) \\
2 & & Muy Buena (80 a 89) \\
3 & & Buena (70 a 79$)$ \\
4 & & Regular (60 a 69$)$
\end{tabular}

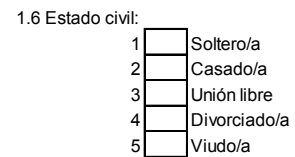

1.7 Teléfonos:

Celular:

Fijo:

Otro:

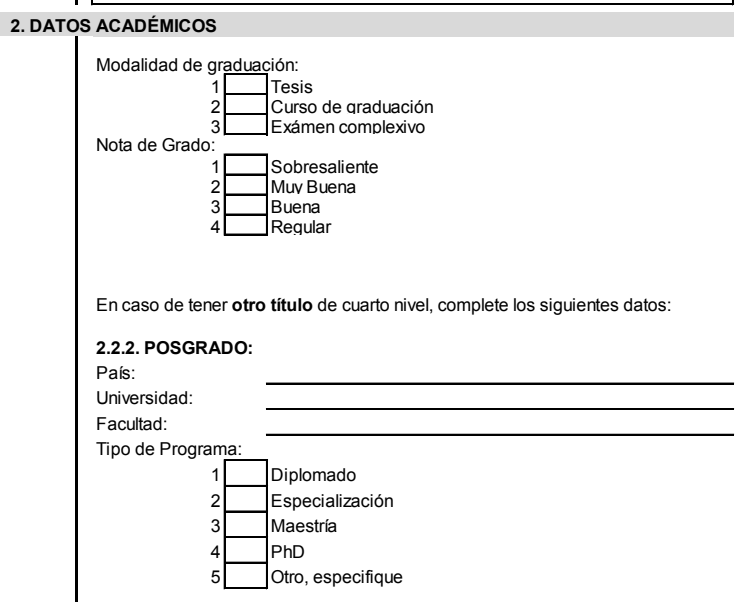

Modalidad de Estudios:

$1 \square$ Presencial

2 Semipresencia

Titulo obtenido:

A distancia

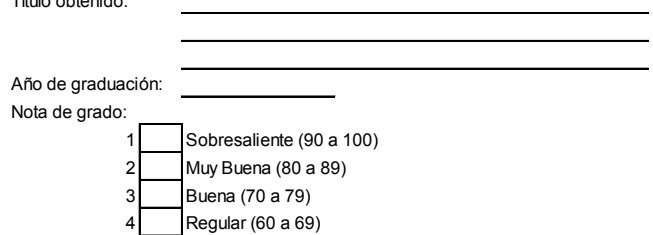


doi: http://dx.doi.org/10.15359/ree.21-3.13

URL: http://www.una.ac.cr/educare

CORREO: educare@una.cr

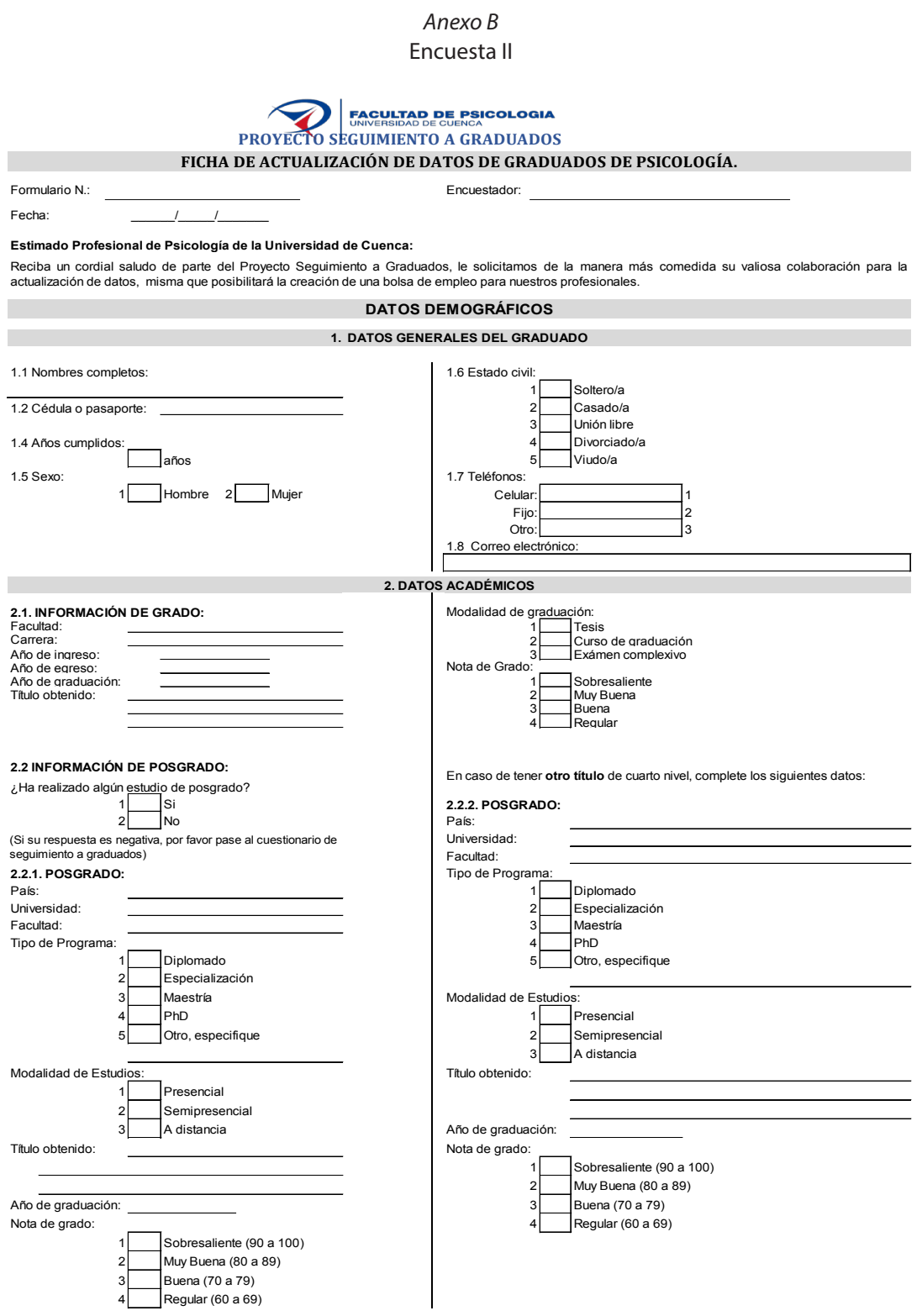

\begin{tabular}{l|l}
\hline 24 & Guido Leonel Rosales-Jaramillo, Andrea Yesenia Rodal-Genovez, Viviana Tatiana Chumbi-Toledo y Román Mauricio Buñay-Andrade
\end{tabular} 